\title{
Meten van lichamelijke activiteit van kinderen: vragenlijsten vergeleken met versnellingsmeter
}

\author{
D.F. Schokker, ${ }^{1}$ K.D. Hekkert, ${ }^{1}$ P.L. Kocken, ${ }^{1}$ C.L. van den Brink, ${ }^{2}$ S.I. de Vries ${ }^{1}$
}

\begin{abstract}
Inleiding: De mate van overeenstemming tussen lichamelijke activiteit van kinderen gemeten door een versnellingsmeter en twee veelgebruikte vragenlijsten werd onderzocht. Methoden: De gegevens van 116 zes- tot en met elfjarige kinderen zijn geanalyseerd. Lichamelijke activiteit is gemeten met behulp van een ActiGraph versnellingsmeter, de Standaardvraagstelling Bewegen Jeugd en de vragenset uit Ongevallen en Bewegen in Nederland (OBiN). De uitkomstmaten van de twee vragenlijsten zijn vergeleken met die van de versnellingsmeter. Resultaten: Op basis van de ActiGraph gegevens voldeed 2\% van de kinderen aan de Nederlandse Norm Gezond Bewegen (NNGB), volgens de Standaardvraagstelling $88 \%$ en volgens OBiN 17\%. De hoogste correlatie werd gevonden tussen ActiGraph en Standaardvraagstelling in aantal uur actief per dag $(\rho=0,35)$, gevolgd door ActiGraph en Standaardvraagstelling in aantal dagen per week minimaal 60 minuten actief $(\rho=0,19)$. Volgens de Standaardvraagstelling waren kinderen gemiddeld 2,2 uur per dag actief, volgens de ActiGraph was dat 0,5 uur. Gekeken naar het aantal dagen per week waarop kinderen minimaal 60 minuten actief waren, was het verschil tussen ActiGraph en Standaardvraagstelling 5,6 dagen per week (95\% BI: 1,6-9,7) en tussen ActiGraph en OBiN 3,7 dagen per week (95\% BI: -1,1-8,5). Conclusie: Er zijn grote verschillen gevonden in de mate van lichamelijke activiteit van kinderen op basis van de drie meetinstrumenten. In het algemeen schatten de vragenlijsten de mate van lichamelijke activiteit hoger in dan de versnellingsmeter. De ontwikkelingen op het gebied van objectieve meetinstrumenten zullen bijdragen aan het verbeteren van het meten van lichamelijke activiteit in grootschalig epidemiologisch onderzoek.
\end{abstract}

Trefwoorden: lichamelijke activiteit, vragenlijst, versnellingsmeter, Nederlandse Norm Gezond Bewegen, kinderen

\section{INLEIDING}

De aandacht voor het stimuleren van bewegen is in de laatste jaren toegenomen, onder meer als gevolg van de gestegen prevalentie van overgewicht $t^{1,2}$ en de ambities om de fitheid van de bevolking te verhogen in het kader van het Olympisch plan 2028. ${ }^{3}$ Ook de landelijke nota gezondheidsbeleid legt het accent op bewegen. ${ }^{4}$ De jeugd krijgt speciale aandacht, omdat deze groep volgens de Nederlandse Norm Gezond Bewegen (NNGB) te weinig beweegt. $^{3}$

De NNGB wordt in Nederland gebruikt als richtlijn voor gezond beweeggedrag. ${ }^{5,6}$ Volgens deze norm moeten kinderen elke dag minimaal 60 minuten tenminste matig intensief lichamelijk actief zijn om op lange termijn gezond te blijven. Onder tenminste matig intensieve activiteiten vallen activiteiten die minimaal zo inspannend zijn als stevig doorlopen of -fietsen, zoals hinkelen, voetballen of dansen. Om te bepalen of kinderen voldoen aan de NNGB worden verschillende meetinstrumenten gebruikt, zoals vragenlijsten en versnellingsmeters. Twee

1 TNO, Leiden

${ }^{2}$ RIVM, Bilthoven veelgebruikte Nederlandse vragenlijsten voor het schatten van de mate van lichamelijke activiteit van kinderen zijn de Standaardvraagstelling Bewegen uit de Lokale en Nationale Monitor Jeugdgezondheid van GGD'en (Standaardvraagstelling $)^{7}$ en de vragenset uit de monitor Bewegen en Gezondheid van het permanente onderzoek Ongevallen en Bewegen in Nederland (OBiN). ${ }^{8}$ Daarnaast wordt in toenemende mate gebruik gemaakt van versnellingsmeters om de mate van lichamelijke activiteit van kinderen te schatten. Versnellingsmeters worden ook veelvuldig gebruikt als referentiemethode om andere meetinstrumenten mee te vergelijken. ${ }^{9,10}$

De twee vragenlijsten en de versnellingsmeter meten verschillende aspecten van lichamelijke activiteit: duur, frequentie, intensiteit en/of type activiteit. De Standaardvraagstelling levert informatie over de duur en frequentie van vier verschillende typen lichamelijke activiteit per week, maar niet over de intensiteit hiervan. Met name bij buitenspelen, ${ }^{11}$ de gymles op school ${ }^{12}$ en ook bij lopen naar school zal meestal niet de volledige gerapporteerde tijdsduur worden besteed aan tenminste matig intensieve activiteiten. Dat is echter niet te achterhalen op basis van de antwoordcategorieën van de vragenlijst en 
wordt niet meegenomen bij het bepalen of aan de NNGB wordt voldaan. De OBiN-vragenset bevat met name informatie over de frequentie. Informatie over duur en intensiteit is beperkt. Over type activiteit is geen informatie beschikbaar. Met een versnellingsmeter is informatie over de duur, frequentie en intensiteit van lichamelijke activiteit beschikbaar, maar niet direct over het type activiteit. Daarnaast onderschat een versnellingsmeter de intensiteit van fietsen en wordt deze niet gedragen met zwemmen omdat hij niet goed tegen water kan. ${ }^{13,14}$

Het gebruik van verschillende meetinstrumenten levert aanzienlijke verschillen op in het percentage kinderen dat voldoet aan de NNGB. ${ }^{15}$ Hoewel dat gezien de verschillen tussen de meetinstrumenten niet verwonderlijk is, worden de uitkomsten vaak wel met elkaar vergeleken. Studies waarin de Standaardvraagstelling wordt gebruikt, komen op een relatief hoog percentage kinderen dat voldoet aan de NNGB: $80-90 \% .{ }^{16-18}$ Als het halen van de NNGB wordt berekend aan de hand van de vraag "Hoeveel dagen per week denk je tenminste 1 uur lichamelijk actief te zijn?", zoals in de OBiN-vragenset, is circa 20-25\% van de kinderen in de leeftijd 8-12 jaar normactief. ${ }^{19,20}$ Een studie waarin gebruik is gemaakt van versnellingsmeters en dagboekjes liet zien dat slechts 3\% van de zes- tot en met elfjarige kinderen uit stedelijke achterstandswijken aan de NNGB voldoet. ${ }^{21}$

Omdat de keuze voor een meetinstrument grote invloed heeft op het gevonden percentage normactieve kinderen is het van belang om goed inzicht te hebben in de eigenschappen van verschillende meetinstrumenten en hun invloed op de bevindingen. De doelstelling van dit artikel is het bepalen van de mate van overeenstemming tussen de lichamelijke activiteit van kinderen gemeten met een ActiGraph versnellingsmeter en met twee veelgebruikte Nederlandse vragenlijsten, de Standaardvraagstelling en OBiN. Aan de hand hiervan worden aanbevelingen geformuleerd over het meten van lichamelijke activiteit van kinderen.

\section{METHODEN}

\section{Onderzoekspopulatie}

Voor dit artikel zijn meetgegevens uit drie verschillende studies geanalyseerd, te weten: BOS Maassluis, Wijk \& Jeugd en Overgewicht in het BasisOnderwijs (OBO). De meting van BOS Maassluis ${ }^{22}$ werd uitgevoerd in april 2007 in de groepen 4 van twee basisscholen in een achterstandswijk in Maassluis. Van hen zijn 55 kinderen, die allen een versnellingsmeter droegen, opgenomen in de analyses. De meting van Wijk \& Jeugd ${ }^{23}$ vond plaats in tien achterstandswijken verdeeld over vijf steden, van januari tot en met april 2009. Kinderen uit groep 3 tot en met 7 van in totaal twintig basisscholen werden gevraagd om deel te nemen. De totale onderzoekspopulatie bestond uit 927 kinderen. Een random subgroep van hen $(n=97)$ droeg een versnellingsmeter. De meting voor de OBO-studie (nog niet gepubliceerd) werd uitgevoerd tussen november 2009 en januari 2010 bij kinderen in groep 6 van 44 basisscholen verdeeld over Nederland. In totaal deden aan OBO 1104 kinderen mee. Van hen droeg een random subgroep van 159 kinderen een versnellingsmeter.

\section{Meetinstrumenten}

In de studies is de ActiGraph ééndimensionale versnellingsmeter (ActiGraph GT1M, Pensacola, FL, USA) gebruikt. De ActiGraph geeft informatie over de frequentie, duur en intensiteit van lichamelijke activiteit op basis van versnellingen in het verticale vlak. Verschillende studies tonen aan dat de ActiGraph een betrouwbaar en valide instrument is om lichamelijke activiteit bij basisschoolkinderen te meten. ${ }^{9,10}$ De ActiGraph werd bevestigd aan een verstelbare elastieken band en gedragen op de rechterheup en was ingesteld op een sampling interval van 15 seconden: het gemiddelde aantal counts werd per 15 seconden opgeslagen. Hierdoor worden ook korte perioden met een hoge beweegintensiteit, die bij kinderen veel voorkomen, geregistreerd. De ActiGraph is niet waterbestendig en kon daarom niet gedragen worden tijdens activiteiten als douchen en zwemmen. Bij BOS Maassluis en Wijk \& Jeugd werd de kinderen gevraagd om de ActiGraph gedurende acht opeenvolgende dagen te dragen, bij OBO tenminste drie dagen waarvan één weekenddag.

De twee vragenlijsten werden bij BOS Maassluis (op de computer) en OBO (op papier) ingevuld door kinderen onder begeleiding van een volwassene. Bij Wijk \& Jeugd vulden ouders een schriftelijke vragenlijst in. Alle vragenlijsten bevatten de Standaardvraagstelling Bewegen en de OBiN-vragenset om inzicht te krijgen in de lichamelijke activiteit van kinderen.

De Standaardvraagstelling ${ }^{7}$ vraagt naar de frequentie (aantal dagen of keer per week) en de duur (gemiddelde duur per dag of keer) van een viertal activiteiten: lopen en/of fietsen naar school, sporten op school, sporten als lid van een sportvereniging en buitenspelen. De referentieperiode hierbij is de afgelopen week. Bij BOS Maassluis en Wijk \& Jeugd werd de originele Standaardvraagstelling gebruikt. Bij OBO werd de vraag: "Hoe lang ben je lopend of fietsend per dag onderweg van huis naar school 
en van school naar huis? Tel de minuten bij elkaar op van één dag (ochtend en middag)" vereenvoudigd tot "Hoe lang ben je dan meestal onderweg van huis naar school?", waarbij de antwoordcategorieën gelijk werden gehouden.

In de OBiN-vragenset ${ }^{8}$ staan twee vragen om te bepalen of een kind voldoet aan de NNGB: het aantal dagen per week waarop een kind in de zomer dan wel de winter tenminste 60 minuten per dag lichaamsbeweging heeft die minstens even inspannend is als stevig doorlopen of fietsen.

Naast lichamelijke activiteit bevatten de vragenlijsten vragen over demografische kenmerken: leeftijd, geslacht en geboorteland van het kind, de vader en de moeder.

\section{Dataverwerking}

Alleen de kinderen die de ActiGraph tenminste twee weekdagen en één weekenddag gedurende minimaal 500 minuten per dag hebben gedragen, zijn opgenomen in de analyses. Na inspectie van de draagtijd van de ActiGraphs zijn alleen waarnemingen tussen 7 uur 's morgens en 23 uur 's avonds meegenomen. De leeftijdspecifieke afkapwaarden van Trost et al. ${ }^{24}$ zijn gebruikt om de tijd die kinderen besteedden aan minimaal matig intensieve activiteiten ( $\geq 3$ metabole equivalenten (METs)) te bepalen. Op basis hiervan werden twee uitkomstmaten berekend: het gemiddeld aantal uur per dag dat kinderen gedurende de meetperiode tenminste matig intensief actief waren (ActiGraph Actief) en het aantal dagen per week waarop de kinderen in totaal minimaal 60 minuten tenminste matig intensieve lichaamsbeweging hadden (ActiGraph Normactief). ActiGraph Actief werd berekend door alle perioden van 15 seconden waarin een intensiteit van tenminste 3 METs is geregistreerd op te tellen, om te rekenen naar totaal aantal uur en te delen door het aantal meetdagen. Indien minder dan 7 dagen gemeten was, werd ActiGraph Normactief bepaald door het aantal dagen in de meetperiode waarop de norm gehaald werd om te rekenen naar het aantal dagen waarop de norm gehaald zou worden als er een periode van 7 dagen gemeten zou zijn.

Ook op basis van de Standaardvraagstelling zijn twee uitkomstmaten bepaald. Standaardvraagstelling Actief is berekend als het gemiddelde aantal uur per dag dat kinderen actief waren, door de som van frequentie maal duur van de vier typen activiteiten te bepalen en te delen door 7 dagen. Standaardvraagstelling Normactief is berekend als het gemiddeld aantal dagen dat kinderen 60 minuten actief waren. Een kind dat per week 200 minuten actief was, was gemiddeld 3,3 dagen $(200 / 60=3,3)$ normactief. Alle waarden boven de 7 zijn afgerond op 7,0.

De uitkomstmaat op basis van de OBiN-vragen is OBiN Normactief. Hiertoe is het gemiddelde bepaald van het aantal dagen per week waarop kinderen normactief zijn in de zomer en in de winter. Door de aard van de OBiN-vraagstelling is er geen OBiN Actief uitkomstmaat.

Voor zowel de ActiGraph, de Standaardvraagstelling als de OBiN-vragenset is bepaald welk percentage van de kinderen normactief was ( 7 dagen per week $\geq 60$ minuten), semi-actief (5-6 dagen), semi-inactief (3-4 dagen) en inactief (0-2 dagen).

\section{Statistische analyse}

De verschillen in demografische kenmerken en lichamelijke activiteit van de kinderen tussen de drie studies zijn getoetst met behulp van ANOVA en Tukey's HSD voor continue variabelen en Chi-kwadraat voor categorische variabelen. Vanwege kleine verschillen in de onderzoeksopzet en -methoden van de drie studies worden de resultaten behalve voor de totale onderzoekspopulatie ook per studie weergegeven. Histogrammen lieten zien dat de uitkomstmaten, met uitzondering van 'Standaardvraagstelling Actief', niet normaal verdeeld waren. Daarom is Spearman's rangcorrelatie bepaald om de uitkomsten van de vragenlijsten en de ActiGraph gegevens te vergelijken. Om inzicht te geven in de mate van overeenkomst tussen twee meetinstrumenten zijn tevens Bland \& Altman grafieken $^{25}$ gemaakt. Het verschil tussen twee meetinstrumenten (bijvoorbeeld $\mathrm{X}_{\text {Standaardvraagstelling }}-\mathrm{X}_{\text {ActiGraph }}$ ) met het bijbehorende $95 \%$ betrouwbaarheidsinterval wordt op de $y$-as uitgezet tegen de gemiddelde waarde van de twee meetinstrumenten op de $\mathrm{X}$-as (bijvoorbeeld $\left(\mathrm{X}_{\text {Standaardvraagstelling }}+\mathrm{X}_{\text {ActiGraph }}\right)$ / 2). Een Bland \& Altman grafiek geeft daarmee inzicht in de mate van overeenstemming, terwijl een (rang-)correlatiecoëfficiënt inzicht geeft in overeenstemming in rangvolgorde (maar niet in de mate van overeenstemming). ${ }^{25,26}$ Alle statistische analyses zijn uitgevoerd in SPSS 17.0 (SPSS Inc., Chicago).

\section{RESULTATEN}

In totaal waren er 125 kinderen die de ActiGraph op tenminste 2 weekdagen en 1 weekenddag minimaal 500 minuten gedragen hadden. Negen van hen hadden zowe de Standaardvraagstelling als de OBiN-vragen niet ingevuld, waardoor zij niet zijn meegenomen in de analyses. Dit resulteerde in een totaal van 116 kinderen: 54 jongens en 62 meisjes met een gemiddelde leeftijd van 9,0 jaar (zie Tabel 1). De kinderen hadden de ActiGraph bij BOS Maassluis en Wijk \& Jeugd op gemiddeld resp. 5,9 en 5,6 dagen gedragen. Bij OBO was dit 3,3 dagen.

Op basis van de ActiGraph gegevens waren de kinderen gemiddeld 0,5 uur per dag tenminste matig intensief actief (zie Tabel 2). Volgens de Standaardvraagstelling waren kinderen gemiddeld 2,2 uur per dag actief. Het aantal dagen per week waarop kinderen normactief waren, varieerde van 1,1 dag per week volgens de ActiGraph tot 4,8 en 6,7 dagen per week volgens respectievelijk de OBiN-vragenset en de Standaardvraagstelling.

Op basis van de ActiGraph was 2\% van de kinderen normactief en $84 \%$ van de kinderen inactief. Volgens de Standaardvraagstelling voldeed $88 \%$ aan de NNGB en was $2 \%$ inactief, terwijl OBiN uitkwam op respectievelijk $17 \%$ normactief en $10 \%$ inactief.

De rangcorrelatie tussen de ActiGraph en de Standaardvraagstelling- en OBiN-uitkomstmaten is weergegeven in Tabel 3. De hoogste rangcorrelatie, met 0,35 een medium effectgrootte, ${ }^{21}$ is gevonden tussen ActiGraphen Standaardvraagstelling Actief $(\mathrm{p}<0,001)$. ActiGraphen Standaardvraagstelling Normactief zijn eveneens significant $(\mathrm{p}<0,05)$ met elkaar gecorreleerd, maar de effectgrootte is beperkt $(\rho=0,19)$. Tussen ActiGraph- en 
Tabel 1 Demografische kenmerken van kinderen in het onderzoek, uitgesplitst naar studie.

\begin{tabular}{|c|c|c|c|c|c|}
\hline & $\begin{array}{l}\text { Totaal } \\
(n=116)\end{array}$ & $\begin{array}{l}\text { BOS Maassluis } \\
(n=42)\end{array}$ & Wijk \& Jeugd $(n=39)$ & $\begin{array}{l}\text { OBO } \\
(n=35)\end{array}$ & p-waarde \\
\hline Geslacht (\% jongens) & $47 \%$ & $48 \%$ & $47 \%$ & $44 \%$ & 0,946 \\
\hline Leeftijd (gem, sd) & $9,0(1,4)$ & $8,3(0,5)^{\#}$ & $9,0(1,3)^{\star}$ & $10,0(1,6)^{\star \#}$ & $<0,001$ \\
\hline Etniciteit (\%) & & & & *\# & 0,001 \\
\hline Autochtoon & $71 \%$ & $62 \%$ & $57 \%$ & $94 \%$ & \\
\hline Allochtoon & $29 \%$ & $38 \%$ & $43 \%$ & $6 \%$ & \\
\hline
\end{tabular}

*Significant verschillend van BOS Maassluis $(p<0,05)$. ${ }^{\#}$ Significant verschillend van Wijk \& Jeugd $(p<0,05)$.

Tabel 2 Lichamelijke activiteit van kinderen in het onderzoek, uitgesplitst naar studie.

\begin{tabular}{|c|c|c|c|c|c|}
\hline & Totaal & BOS Maassluis & Wijk \& Jeugd & OBO & p-waarde \\
\hline ActiGraph & $\mathrm{n}=116$ & $n=42$ & $\mathrm{n}=39$ & $\mathrm{n}=35$ & \\
\hline Actief ( $\geq 3$ METs); uur per dag (gem, sd) & $0,5(0,4)$ & $0,9(0,4)$ & $0,4(0,2)^{\star}$ & $0,3(0,2)^{*}$ & $<0,001$ \\
\hline Normactief; dagen per week (gem, sd) & $1,1(1,9)$ & $2,4(2,4)$ & $0,2(0,6)^{*}$ & $0,4(1,1)^{\star}$ & $<0,001$ \\
\hline Inactief (<3 dagen per week) & $84 \%$ & $62 \%$ & $100 \%$ & $94 \%$ & \\
\hline Semi-inactief (3-4 dagen per week) & $7 \%$ & $17 \%$ & $0 \%$ & $3 \%$ & \\
\hline Semi-actief (5-6 dagen per week) & $7 \%$ & $17 \%$ & $0 \%$ & $3 \%$ & \\
\hline Normactief ( 7 dagen per week) & $2 \%$ & $5 \%$ & $0 \%$ & $0 \%$ & \\
\hline Actief in uur per dag (gem, sd) & $2,2(1,1)$ & $2,8(1,2)$ & $1,8(1,0)^{\star}$ & $1,9(1,0)^{\star}$ & $<0,001$ \\
\hline Normactief in dagen per week (gem, sd) & $6,7(0,9)$ & $6,9(0,3)$ & $6,7(1,0)$ & $6,5(1,3)$ & 0,155 \\
\hline NNGB categorieën & & & & & 0,607 \\
\hline Inactief (<3 dagen per week) & $2 \%$ & $0 \%$ & $3 \%$ & $3 \%$ & \\
\hline Semi-inactief (3-4 dagen per week) & $4 \%$ & $0 \%$ & $6 \%$ & $6 \%$ & \\
\hline Semi-actief (5-6 dagen per week) & $6 \%$ & $5 \%$ & $8 \%$ & $6 \%$ & \\
\hline Normactief (7 dagen per week) & $88 \%$ & $95 \%$ & $83 \%$ & $84 \%$ & \\
\hline OBiN & $n=113$ & $n=42$ & $n=37$ & $n=34$ & \\
\hline NNGB categorieën & & & & & 0,658 \\
\hline Inactief (<3 dagen per week) & $10 \%$ & $12 \%$ & $5 \%$ & $12 \%$ & \\
\hline Semi-inactief (3-4 dagen per week) & $34 \%$ & $36 \%$ & $32 \%$ & $35 \%$ & \\
\hline Semi-actief (5-6 dagen per week) & $39 \%$ & $38 \%$ & $49 \%$ & $29 \%$ & \\
\hline Normactief (7 dagen per week) & $17 \%$ & $14 \%$ & $14 \%$ & $24 \%$ & \\
\hline
\end{tabular}

*Significant verschillend van BOS Maassluis $(p<0,05)$.

Tabel 3 Correlatie van de ActiGraph met de Standaardvraagstelling en OBiN uitkomstmaten (Spearman's rho) in het onderzoek, uitgesplitst naar studie.

\begin{tabular}{|c|c|c|c|c|c|c|c|c|c|c|}
\hline & & \multicolumn{6}{|c|}{ Standaardvraagstelling $(\mathrm{n}=110)$} & \multirow{2}{*}{\multicolumn{3}{|c|}{$\begin{array}{c}\text { OBiN }(n=113) \\
\text { Normactief } \\
\text { (dagen / week) }\end{array}$}} \\
\hline & & \multicolumn{3}{|c|}{$\begin{array}{l}\text { Actief } \\
\text { (uur / dag) }\end{array}$} & \multicolumn{3}{|c|}{$\begin{array}{c}\text { Normactief } \\
\text { (dagen / week) }\end{array}$} & & & \\
\hline & & BOS & WJ & OBO & BOS & WJ & OBO & BOS & WJ & OBO \\
\hline (aantal uur per dag) & Per studie & 0,26 & $-0,07$ & 0,27 & - & - & - & - & - & - \\
\hline ActiGraph Normactief & Totaal & \multicolumn{3}{|c|}{-} & \multicolumn{3}{|c|}{$0,191^{*}$} & \multicolumn{3}{|c|}{0,081} \\
\hline (aantal dagen per week) & Per studie & - & - & - & 0,25 & $-0,05$ & 0,14 & $0,32^{*}$ & $-0,03$ & 0,02 \\
\hline
\end{tabular}

${ }^{*} \mathrm{p}<0,05 ;{ }^{* *} \mathrm{p}<0,001$.

OBiN Normactief $(\rho=0,08)$ werd geen significante rangcorrelatie gevonden.

In figuur 1 worden de uitkomstmaten ActiGraph- en Standaardvraagstelling Actief in een Bland \& Altman grafiek met elkaar vergeleken. In deze grafiek is te zien dat kinderen volgens de Standaardvraagstelling gemiddeld bijna 1 uur en 40 minuten (gemiddeld verschil) per dag langer actief zijn dan op basis van de ActiGraph. Het $95 \%$ betrouwbaarheidsinterval, van -2 tot +2 standaarddeviaties, geeft aan dat het verschil in lichamelijke activiteit op basis van de Standaardvraagstelling en de ActiGraph bij 95\% van de kinderen varieerde tussen de -0,5 en $+3,8$ uur. Het verschil tussen ActiGraph- en Standaardvraagstelling Actief is niet constant. Bij kinderen met een hoger gemiddelde op de twee meetinstrumenten (een hogere waarde op de $\mathrm{x}$-as) is het verschil tussen de meetinstrumenten groter (een hogere waarde op de y-as). Dit komt met name door de grotere spreiding van lichamelijke activiteit op basis van de Standaardvraagstelling. Volgens de Standaardvraagstelling waren kinderen gemiddeld 2,2 uur per dag actief met een standaarddeviatie van 1,1 , terwijl dit volgens de ActiGraph gemiddeld 0,5 uur met een standaarddeviatie van 0,4 was (Tabel 2).

In figuur 2 worden de uitkomstmaten ActiGraph- en Standaardvraagstelling Normactief vergeleken, beiden in het aantal dagen per week dat kinderen normactief zijn. Het verschil in uitkomstmaten tussen deze meetinstrumenten bedraagt gemiddeld 5,6 dagen per week en het $95 \%$ BI van dit verschil loopt van 1,5 tot 9,7 dagen. Het geknikte patroon in de figuur is ontstaan doordat een groot deel van de kinderen op basis van de Standaardvraagstelling zeven dagen per week normactief is $(88 \%)$, 


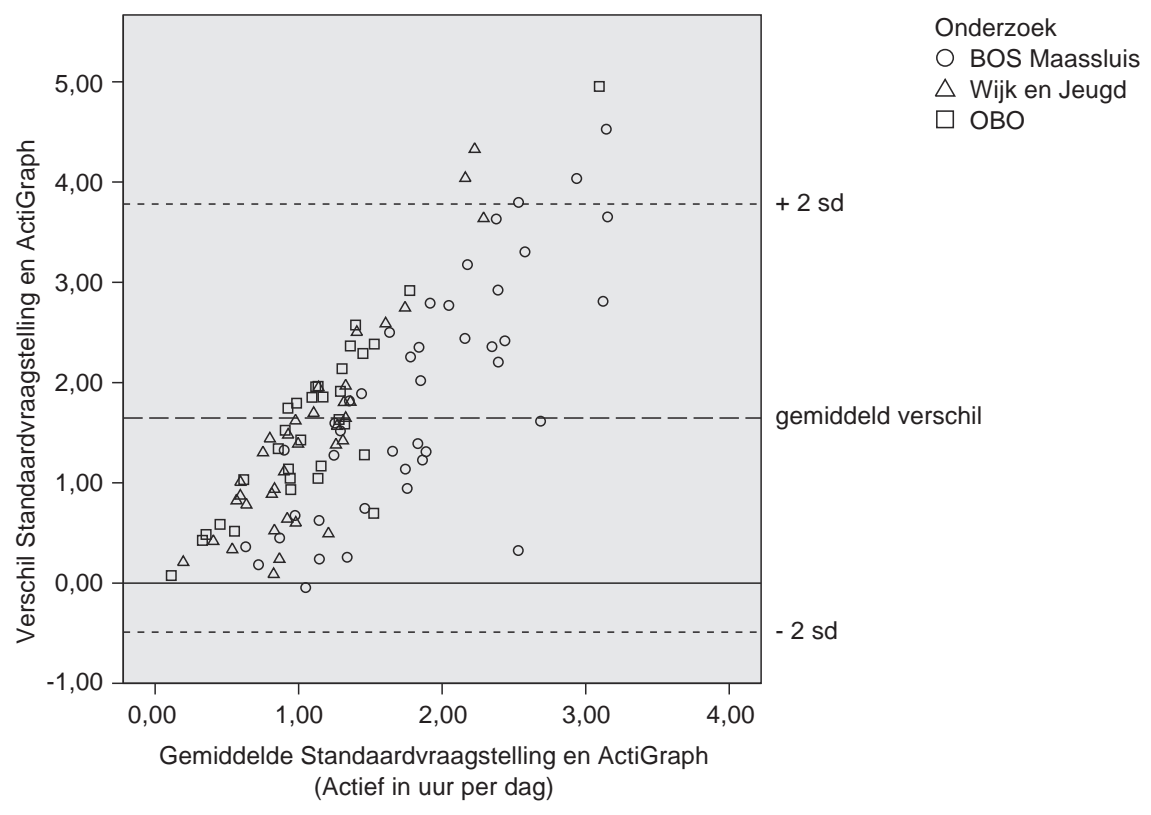

Figuur 1 Actief in aantal uur per dag: het verschil tussen de Standaardvraagstelling en de ActiGraph versnellingsmeter uitgezet tegen het gemiddelde van de Standaardvraagstelling en de ActiGraph (Bland \& Altman grafiek).

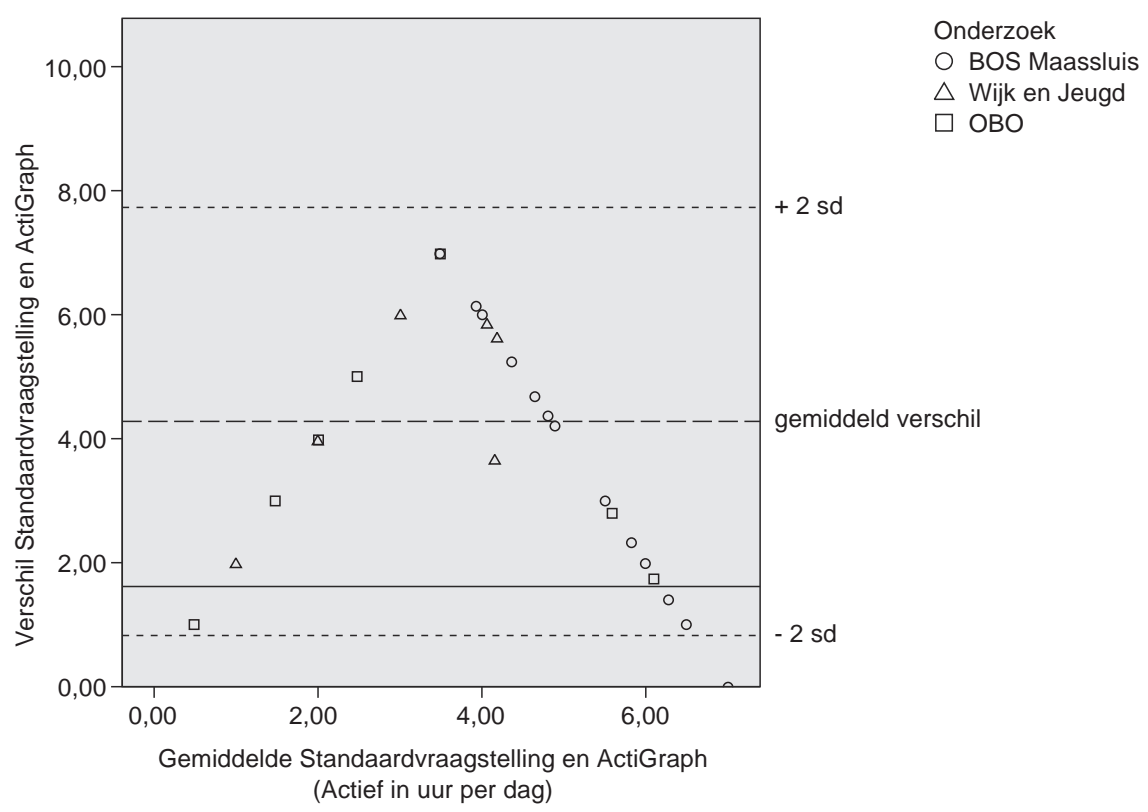

Figuur 2 Normactief in aantal dagen per week: het verschil tussen de Standaardvraagstelling en de ActiGraph versnellingmeter uitgezet tegen het gemiddelde van de Standaardvraagstelling en de ActiGraph (Bland \& Altman grafiek).

terwijl op basis van de ActiGraph zeven op de tien kinderen op geen enkele dag normactief is. Een groot aantal datapunten, 64 van de 110, overlapt elkaar in de top.

De Bland \& Altman grafiek waarin het aantal dagen normactief per week op basis van de ActiGraph met OBiN Normactief wordt vergeleken (figuur 3), lijkt op het oog enigszins op figuur 2. Het gemiddelde verschil tussen OBiN- en ActiGraph Normactief is met 3,7 dagen per week (95\% BI: -1,1-8,5 dagen) echter wat kleiner dan tussen ActiGraph- en Standaardvraagstelling Normactief.

\section{DISCUSSIE}

In dit artikel is gekeken naar de mate van overeenstemming tussen de lichamelijke activiteit van kinderen zoals gemeten met een ActiGraph versnellingsmeter enerzijds en een tweetal vragenlijsten anderzijds. Er waren grote verschillen in het percentage kinderen dat voldoet aan de NNGB en in de mate van lichamelijke activiteit van kinderen al naar gelang het gebruikte meetinstrument, waarbij het percentage kinderen dat voldoet aan de NNGB op basis van de vragenlijsten (Standaardvraagstelling: $88 \%$, OBiN: $17 \%$ ) aanzienlijk hoger is dan op 


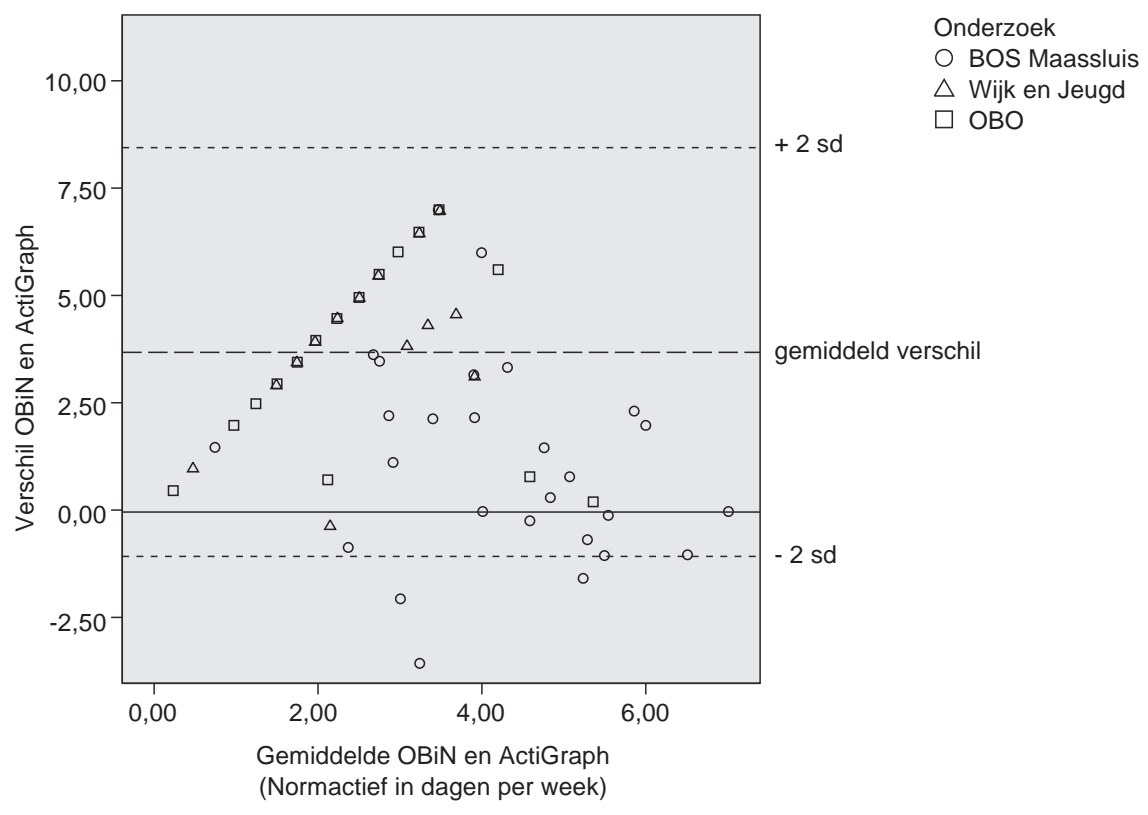

Figuur 3 Normactief in aantal dagen per week: het verschil tussen de OBiN-vragenset en de ActiGraph versnellingsmeter uitgezet tegen het gemiddelde van OBiN en de ActiGraph (Bland \& Altman grafiek).

basis van de versnellingsmeter (ActiGraph: 2\%). De gevonden percentages zijn vergelijkbaar met andere studies die deze meetinstrumenten gebruikten. ${ }^{16-21}$ In een vergelijking tussen een Nederlandse vragenlijst (de AQuAA) en een versnellingsmeter vonden Slootmaker et al. ${ }^{28}$ ook bij adolescenten grote verschillen tussen de mate van lichamelijke activiteit met de verschillende meetinstrumenten.

De overeenstemming in de rangvolgorde van lichamelijke activiteit, af te lezen uit de grootte van Spearman's rho, was sterker tussen de ActiGraph en de Standaardvraagstelling dan tussen de ActiGraph en OBiN. Echter, uit de Bland \& Altman grafieken bleek dat het verschil tussen de ActiGraph en de Standaardvraagstelling groot is: volgens de ActiGraph waren kinderen gemiddeld 1,7 uur per dag minder actief dan op basis van de Standaardvraagstelling. Ook in het aantal dagen per week dat kinderen normactief zijn, werden grote verschillen gevonden tussen deze twee meetinstrumenten: gemiddeld 1,1 dag per week volgens de ActiGraph en 6,7 dagen per week volgens de Standaardvraagstelling. Hoewel de overeenstemming in de rangvolgorde tussen de ActiGraph en OBiN zeer zwak was $(\rho=0,08)$, blijkt uit de Bland \& Altman grafieken dat het gemiddelde verschil tussen de ActiGraph en OBiN Normactief met 3,7 dagen per week kleiner was dan tussen de ActiGraph en de Standaardvraagstelling. Kortom: de OBiN-vragenset overschatte het aantal dagen waarop de norm gehaald wordt minder dan de Standaardvraagstelling, terwijl de rangvolgorde van lichamelijke activiteit op basis van de Standaardvraagstelling meer overeenkwam met de rangvolgorde van de versnellingsmeter dan de OBiN-vragenset deed.

Het uitgevoerde onderzoek kent een aantal zwakke punten. Allereerst is er gebruik gemaakt van data van drie verschillende studies die niet exact dezelfde methoden hebben gebruikt. Zo zijn er verschillen in de wijze van afname van de vragenlijsten, was in één van de studies de Standaardvraagstelling over actief transport aangepast en verschilde de draagtijd van de ActiGraph. De draagtijd lijkt echter geen invloed te hebben gehad op de mate van overeenstemming tussen de drie meetinstrumenten. Daarnaast werden de studies in verschillende jaren en seizoenen uitgevoerd. Idealiter zou informatie over het gemiddelde beweeggedrag van kinderen over een langere periode beschikbaar zijn. De ActiGraph wordt een aantal week- en weekenddagen gedragen en geeft daarmee een beeld over die dagen waarop de versnellingsmeter is gedragen. De Standaardvraagstelling heeft als referentieperiode 'de afgelopen week'. Deze beide instrumenten zijn daarmee gevoelig voor seizoensinvloeden en andere oorzaken voor tijdelijke veranderingen in lichamelijke activiteit (zoals ziekte, vakantie of een drukke periode op school). Uit de maand- en seizoensoverzichten van het $\mathrm{KNMI}^{29}$ blijkt dat de maand waarin BOS Maassluis werd uitgevoerd (april 2007) uitzonderlijk zacht, zonnig en droog was, terwijl in de maanden waarin Wijk en Jeugd (januari - april 2009) en OBO (november 2009 - januari 2010) werden uitgevoerd zowel de gemiddelde temperatuur als het aantal zonuren lager was dan in april 2007, en het aantal millimeter neerslag beduidend hoger. In de resultaten is terug te vinden dat kinderen in het BOS Maassluis onderzoek volgens de ActiGraph en de Standaardvraagstelling actiever waren dan in de andere onderzoeken. De OBiN-vragenset vraagt voor zomer en winter naar het gemiddelde aantal normactieve dagen per week. Daardoor lijkt deze vragenlijst minder gevoelig voor schommelingen in lichamelijke activiteit. Inderdaad werden met de OBiN-vragenset geen verschillen tussen de studies gevonden. 
Op basis van de versnellingsmetergegevens zou ten onrechte kunnen worden geconcludeerd dat in werkelijkheid' slechts $2 \%$ van de kinderen voldoende beweegt om op de lange termijn gezond te blijven, omdat zij -volgens de versnellingsmeters- voldoen aan de NNGB. De NNGB is echter niet gebaseerd op objectief gemeten beweeggedrag, maar op basis van consensus onder experts. ${ }^{5}$ De eerste grote epidemiologische studies waarin lichamelijke activiteit wordt gemeten met versnellingsmeters zijn inmiddels gaande, maar het zal nog jaren duren eer een norm ontwikkeld kan worden op basis van de dosis-respons relatie tussen objectief gemeten lichamelijke activiteit en gezondheidsuitkomsten op langere termijn. De versnellingsmeter en de twee vragenlijsten geven informatie over verschillende aspecten van lichamelijke activiteit. Dat de uitkomsten van deze meetinstrumenten verschillen, wordt bevestigd door de Bland \& Altman grafieken. Idealiter bevat een Bland \& Altman grafiek een horizontale lijn die een gemiddeld verschil van nul tussen twee meetinstrumenten aangeeft, met daaromheen een gelijkmatig verdeelde puntenwolk met acceptabele (kleine) afwijkingen van het gemiddelde. De grafieken in deze studie lieten dit beeld niet zien. Hierdoor kan geconcludeerd worden dat de hier gepresenteerde uitkomsten op basis van deze meetinstrumenten niet onderling uitwisselbaar zijn. Dit benadrukt dat alleen bevindingen van studies waarin hetzelfde meetinstrument gebruikt is, vergelijkbaar zijn.

Op dit moment is er nog geen consensus over een 'gouden standaard' voor het meten van lichamelijke activiteit van kinderen in het dagelijks leven. Dubbel gelabeld water wordt wel genoemd als standaard voor het bepalen van energieverbruik, maar deze methode is duur, zeer bewerkelijk en geeft geen inzicht in de frequentie, intensiteit, duur en type lichamelijke activiteit. ${ }^{15}$ Het zou dan ook de voorkeur verdienen dat internationaal consensus wordt verkregen over (de ontwikkeling van) een standaard voor gebruik in het dagelijks leven, zodat bestaande meetinstrumenten daarmee vergeleken kunnen worden en meer inzicht wordt verkregen in de positieve en negatieve eigenschappen van deze instrumenten. In het hier gepresenteerde onderzoek is de ActiGraph als referentiemethode gebruikt, maar zoals aangegeven heeft ook deze nadelen. Toch lijkt deze versnellingsmeter een goed uitgangspunt, waarbij aan verdere optimalisering van dit meetinstrument wordt gewerkt door ontwikkeling en toepassing van geavanceerde statistische modellen als patroonherkenning ${ }^{30}$ en technologische innovaties als de drie-assige versnellingsmeter en gecombineerde draagbare sensoren, zoals een Global Positioning System (GPS) en hartslagmeter. Hiermee wordt naast duur, frequentie en intensiteit het gewenste inzicht in type lichamelijke activiteit verkregen.

\section{CONCLUSIES}

Er zijn grote verschillen in de mate van lichamelijke activiteit van kinderen op basis van de in deze studie betrokken meetinstrumenten. Daarbij blijkt in het algemeen dat met vragenlijsten de mate van lichamelijke activiteit aanzienlijk hoger wordt ingeschat dan met een versnellingsmeter. De ActiGraph versnellingsmeter geeft gedetailleerde, objectieve informatie over de mate van lichamelijke activiteit. Met de Standaardvraagstelling wordt inzicht verkregen in de duur en frequentie van vier verschillende typen lichamelijke activiteit; deze komt qua rangvolgorde meer overeen met de ActiGraph dan OBiN. De OBiN-vragenset geeft informatie over het aantal dagen waarop de beweegnorm wordt gehaald: de overschatting hiervan ten opzichte van de ActiGraph is minder groot dan met de Standaardvraagstelling.

\section{AANBEVELINGEN}

Aanbevolen wordt om in publicaties duidelijk weer te geven welk meetinstrument gebruikt is om lichamelijke activiteit te meten. Resultaten kunnen alleen worden vergeleken als hetzelfde meetinstrument is gebruikt. Door ontwikkelingen op het gebied van objectieve meetinstrumenten kan het meten van lichamelijke activiteit verbeterd worden.

\section{ABSTRACT}

Measuring physical activity in children: questionnaires vs accelerometer

Background: The aim is to determine the degree of agreement between children's physical activity measured by an accelerometer and by two common Dutch questionnaires. Methods: Data from 116 six- to eleven year old children were analyzed. Physical activity was measured using an ActiGraph accelerometer and the questionnaires 'Standaardvraagstelling Bewegen Jeugd' and 'Ongevallen en Bewegen in Nederland' (OBiN). Spearman's rho and Bland \& Altman plots were used to compare the outcome variables from the ActiGraph with those of the questionnaires. Results: Based on ActiGraph data, $2 \%$ of the children met the Dutch Norm for Healthy Physical Activity (NNGB), according to the Standaardvraagstelling $88 \%$ and according to OBiN $17 \%$. The highest rank correlation was found between ActiGraph and Standaardvraagstelling in number of active hours per day $(\rho=0,35)$, followed by ActiGraph and Standaardvraagstelling in number of days per week with a minimum of 60 minutes active $(\rho=0,19)$. According to the Standaardvraagstelling, children were active 2.2 hours per day, according to the ActiGraph this was 0.5 hours. In the number of days per week with at least 60 minutes active, the difference between ActiGraph and Standaardvraagstelling was 5.6 days (95\% CI: 1.6-9.7) and between ActiGraph and OBiN this was 3.7 days (95\% CI: -1.1-8.5). Conclusion: Large differences were found in the physical activity level in children based on the different measurement instruments involved in the study. Generally, the questionnaires seemed to overestimate the physical activity level based on the accelerometer data. Developments in the area of objective measuring instruments will contribute to improve the physical activity norm and the measurement of physical activity in large scale epidemiological studies.

Keywords: physical activity, questionnaire, accelerometer, Nederlandse Norm Gezond Bewegen, children 


\section{LITERATUUR}

1. TNO. Factsheet Resultaten Vijfde Landelijke Groeistudie TNO. Leiden: TNO, 2010.

2. Hurk van den $K$, Dommelen van $P$, Wilde de JA et al. Prevalentie overgewicht en obesitas bij jeugdigen 4-15 jaar in de periode 2002-2004. Leiden: TNO Kwaliteit van Leven, 2006.

3. $\mathrm{NOC}^{\star} \mathrm{NSF}$. Olympisch Plan 2028. Heel Nederland naar Olympisch niveau. Papendal: NOC ${ }^{\star}$ NSF, 2009.

4. Ministerie van VWS. Gezondheid dichtbij. Landelijke nota gezondheidsbeleid. Den Haag: VWS, 2011.

5. Kemper HCG, Ooijendijk WTM, Stiggelbout M. Hoeveel lichaamsbeweging is gezond? Richtlijnen voor jong en oud. Lichamelijke Opvoeding 2000;1:4-9.

6. Wendel-Vos GCW. Hoeveel mensen zijn voldoende lichamelijk actief? In: Volksgezondheid Toekomst Verkenning, Nationaal Kompas Volksgezondheid. Bilthoven: RIVM, 2008. www.nationaalkompas.nl/gezondheidsdeterminanten/leefstijl/lichamelijke-activiteit.

7. Indicatoren voor de Monitor Jeugdgezondheid. Standaardvraagstelling Bewegen. www.monitorgezondheid.nl/jeugdindicatoren.aspx.

8. Hildebrandt VH, Chorus AMJ, Stubbe JH. Trendrapport Bewegen en Gezondheid 2008/2009. Leiden: TNO Kwaliteit van Leven, 2010.

9. Vries SI de, Bakker I, Hopman-Rock M, Hirasing RA, Mechelen $W$ van. Clinimetric review of motion sensors in children and adolescents. J Clin Epidemiol 2006;59:670-80.

10. Vries SI de, Hirtum HWJEM van, Bakker I et al. Validity and reproducibility of motion sensors in youth: a systematic update. Med Sci Sports Exerc 2009;41:818-27.

11. Jans $L$, Borghouts LB. Volop beweging op het schoolplein? JSW 2011;95:34-7.

12. Slingerland M, Oomen J, Borghouts LB. Physical Activity Levels during Dutch Primary and Secondary School Physical Education. Eur J Sport Sci (accepted).

13. Campbell KL, Crocker PR, McKenzie DC. Field evaluation of energy expenditure in women using Tritrac accelerometers. Med Sci Sports Exerc 2002;34:1667-74.

14. Yokayama Y, Kawamura T, Tamakoshi A et al. Comparison of accelerometry and oxymetry for measuring daily physical activity. Circ J 2002;66:751-4.

15. Vries SI de, Hildebrandt V, Engbers LH, Hekkert KD, Bakker I. Bewegen gemeten: verschillende cijfers door gebrek aan gouden standaard. Tijdschr Gezondheidswet 2009;87:203-6.

16. Bruil J, Dijkstra NS, Jacobusse GW, Kok C et al. Handleiding vragenlijsten Schoolgezondheid Basisonderwijs "Wat doe jij voor je gezondheid?”. Leiden: TNO Preventie \& Gezondheid / GGD-Nederland, 2004.
17. Vogelsang K, Vermeeren M, Hoef RTH van de et al Gezond bewegen in groep 7 en 8 . Tilburg: Fontys Sporthogeschool, 2006.

18. Vries SI de, Overbeek Kvan, Jongert MWA et al Evaluatie Scoren voor Gezondheid. Leiden: TNO Kwaliteit van Leven, 2007.

19. Vries SI de, Chorus AMJ, Verheijden MW. Bewegen in Nederland: jeugdigen van 4-17 jaar. In: Hildebrandt VH, Chorus AMJ, Stubbe JH (red). Trendrapport Bewegen en Gezondheid 2008/2009. Leiden: TNO Kwaliteit van Leven, 2010.

20. Zeijl E, Crone M, Wiefferink K, Keuzenkamp S, Reijneveld $M$. Kinderen in Nederland. Den Haag: SCP, 2005.

21. Vries SI de, Bakker I, Overbeek K van, Hopman-Rock M. Kinderen in prioriteitswijken: lichamelijke (in)activiteit en overgewicht. Leiden: TNO Kwaliteit van Leven, 2005.

22. Hekkert KD, Vries SI de, Bakker I. Overweight and physical activity in children. Comparison between native children and children from a non-western ethnic origin living in a disadvantaged neighbourhood in Maassluis. Leiden: TNO Kwaliteit van Leven, 2007.

23. Vries SI de, Slinger J, Schokker DF, Graham JMA, Pierik FH. Beweegvriendelijke stadswijken voor kinderen; Resultaten van een quasi-experimenteel onderzoek. Leiden: TNO Kwaliteit van Leven, 2010.

24. Trost SG, Pate RR, Freedson PS, Sallis JF, Taylor WC. Using objective physical activity measures with youth: how many days of monitoring are needed? Med Sci Sports Exerc 2000;32: 426-31.

25. Bland JM, Altman DG. Statistical methods for assessing agreement between two methods of clinical measurement. Int J Nurs Stud 2010;47:931-6.

26. Chan YH. Biostatistics 104: Correlational Analysis. Singapore Med J 2003;44(12):614-19.

27. Cohen J. Statistical Power Analysis for the Behavioural Sciences (2nd ed.). New York: Lawrence Erlbaum Associates, 1988.

28. Slootmaker SM, Schuit AJ, Chinapaw MJM, Seidell JC, Mechelen $W$ van. Disagreement in physical activity assessed by accelerometer and self-report in subgroups of age, gender, education and weight status. Int J Beh Nutr Phys Act 2009;6:17.

29. Klimatologie. Maand- en seizoensoverzichten. www.knmi.nl/ klimatologie/maand_en_seizoensoverzichten/index.html.

30. Vries SI de, Galindo Garre F, Engbers LH, Hildebrandt VH, Buuren S van. Evaluation of Neural Networks to Identify Types of Activity Using Accelerometers. Med Sci Sports Exerc 2011; 43:101-7.

\section{CORRESPONDENTIEADRES}

Dieuwke Schokker, TNO, Postbus 2215, 2301 CE Leiden, tel.088-8662701, e-mail: dieuwke.schokker@tno.nl 